\title{
Prevalence and Associations of Hepatitis B Seropositivity in a Rural African Ophthalmic Surgical Population
}

\author{
Obiekwe Okoye ${ }^{1 *}$, Boniface Eze1, Chimdia Ogbonnaya ${ }^{2}$, Chinyelu Ezisi², Olughu Obasi ${ }^{3}$ \\ ${ }^{1}$ Department of Ophthalmology, University of Nigeria, Enugu, Nigeria \\ ${ }^{2}$ Department of Ophthalmology, Federal Teaching Hospital, Abakiliki, Nigeria \\ ${ }^{3}$ Eye Unit, Presbyterian Joint Hospital, Uburu, Nigeria \\ Email: *obiekwe.okoye@unn.edu.ng
}

Received 19 November 2015; accepted 1 February 2016; published 4 February 2016

Copyright (C) 2016 by authors and Scientific Research Publishing Inc.

This work is licensed under the Creative Commons Attribution International License (CC BY). http://creativecommons.org/licenses/by/4.0/

(c) (i) 0 pen Access

\section{Abstract}

Objective: Globally, Hepatitis B virus (HBV) infection remains a public health issue. It is a major cause of morbidity and mortality, especially in developing countries. Working in a healthcare setting particularly in low resource area is a major risk factor for contracting HBV infection. Despite this, routine pre-operative screening for $\mathrm{HBV}$ infection has not yet practiced in many Nigerian hospitals. This study assessed the prevalence and associations of hepatitis B seropositivity in a rural south-eastern Nigerian population of ophthalmic surgical patients. Methods: This was a prospective cross-sectional survey of ophthalmic surgical patients at the Presbyterian Joint Hospital-a rural missionary eye care facility in south-eastern Nigeria, conducted between December 2012 and June 2013. Participant's socio-demographic and clinical data and result of screening for hepatitis B surface antigen (HbSAg) were collected. Results: The participants ( $\mathrm{n}=100$; males, 40; females, 50 ) were aged $52.9 \mathrm{SD} \pm 15.4$ (range 1 - 88 years). They were predominantly farmers $-45 \%$ and traders $-26 \%$ who had cataract $-58 \%$ and glaucoma $-16 \%$ as their leading clinical diagnosis indicating ophthalmic surgical intervention. Of them only $2(2.0 \%)$ were sero-positive for $\mathrm{HbSAg}$. HBV seropositivity was not associated with age, gender or occupation. Conclusion: Though the prevalence of hepatitis B viral infection is low in this study, universal measures to prevent cross infection of the healthcare worker is indicated.

\section{Keywords}

HBV, Prevalence, Associations, Ophthalmic Surgical Patients

\footnotetext{
${ }^{*}$ Corresponding author.

How to cite this paper: Okoye, O., Eze, B., Ogbonnaya, C., Ezisi, C. and Obasi, O. (2016) Prevalence and Associations of Hepatitis B Seropositivity in a Rural African Ophthalmic Surgical Population. Open Journal of Ophthalmology, 6, 6-11. 


\section{Introduction}

Hepatitis B is an infectious inflammatory disease of the liver caused by the hepatitis B virus (HBV) that affects hominoidea (primates), including humans. Originally known as "serum hepatitis" [1], the disease has caused epidemics in parts of Asia and Africa, and it is endemic in China [2]. About a third of the world's population has been infected at one point in their lives [3], including about 400 million who are chronic carriers [4] [5].

The virus is transmitted by exposure to infected blood, blood products, and other body fluids like semen and vaginal fluids. Additional risk factors for contracting HBV infection include perinatal and transplacental transmission, working in a healthcare settings, peritoneal and hemo-dialysis, acupuncture, tattooing, intravenous drug abuse, unprotected surgical procedures, sharing razors or toothbrushes with an infected person and travel to countries where it is endemic [6]-[9].

Prior reports suggest a prevalence of $10 \%$ - 15\% in the average risk Nigerian population [10]. Chronic disease or carrier state, which follows recovery from acute phase, is usually asymptomatic; however carriers remain sero-positive and potentially transmit the infection.

The reported prevalence of HBV infection ranges from $2.0 \%$ in developed countries to $8.0 \%$ in developing countries. In developing countries, HBV infection is often endemic with male gender, older age and lower socio-economic status as important risk factors for infection [11]-[13]. Despite the availability of a safe and effective vaccine, Nigeria has remained hyper-endemic for HBV infection, with an estimated $12.0 \%$ of the population being chronic carriers [14]. Globally HBV infection remains a major public health issue, with new cases still being reported annually [15] [16]. Globally, ophthalmic surgical interventions are among the most frequently performed surgical procedures. The indications include visual restoration, preservation of vision, patients comfort and cosmesis. During these procedures, surgeons and other operating room personnel are exposed to the risk of potential transmission of infection from surgical patients. Despite the high sero-prevalence of HBV infection in the general public and the risk of its peri-operative transmission, currently, in the study center and most other eye care facilities in Nigeria, routine hepatitits B serology is not performed on patients undergoing eye surgeries. Consequently, in Nigeria, HBV sero-prevalence data on ophthalmic surgical patients is scarce. This study is aimed to assess HBV sero-prevalence, and its associations, in a rural ophthalmic surgical patient population in south-eastern Nigeria. The findings will assist ophthalmic surgical care providers and public health workers in preventing peri-operative HBV transmission.

\section{Methods}

\subsection{Background}

Ebonyi state, created on October 1st, 1996 is one of the five component states of Nigeria's south-east geo-political zone. The state is made up of 13 administrative sub-units or Local Government Areas (LGA). The state is located in the tropical rain forest climatic belt. The state's inhabitants are predominantly farmers; however, there are an appreciable number of traders, artisans and civil servants.

There are numerous public and privately-owned eye care centers in Ebonyi state. Of this Presbyterian Joint Hospital-the study center is a rural mission hospital established in 1912 and located in Uburu, Ohaozara LGA. In addition to general medical care, the center provides medical, surgical and refractive eye care to the inhabitants of the LGA and the neighboring eight rural LGAs of Ebonyi State. The hospital's eye care unit is a 20-bed facility manned by one visiting consultant ophthalmologist, one diplomate ophthalmologist, one optometrist, one trained ophthalmic nurse, and six auxiliary nurses.

The study was a prospective descriptive cross-sectional survey of all the patients who accessed ophthalmic surgical care at Presbyterian Joint Hospital between December 1, 2012 and June 1, 2013.

\subsection{Sample Size and Sampling}

Based on the previously reported HBsAg seroprevalence of $1.7 \%$ in a cohort of ophthalmic surgical patients [17] and an error margin of 5\%, a sample size of 26 was envisaged. However all the consecutively presenting, and eligible participants seen at the study center during the study period were recruited to obtain an adjusted sample size of 100 .

Baseline socio-demographic (age, sex, occupation) and clinical (ophthalmic diagnosis and type of surgery) were collected from each participant. Subsequently, each participant was screened for HbSAg seropositivity using Wondfo onestep HBsAg serum/plasma test strip, (Worldbridge Inc, Manila, Phillipines). The test was also 
done based on this principle "Wondfo one step HBsAg serum/Plasma test strip is a rapid Immuno-chromatographic test for visual detection of hepatitis B virus surface antigen (HBs Ag) in serum/plasma samples. The membrane is pre-coated with anti-HBV antibodies on the test line region of the strip. During testing, the specimen reacts with the particle coated with the HBV antibody. The mixture migrates upwards on the membrane chromatographically by capillary action to react with anti-HBV antibodies on the membrane and generate a colored line. Presence of colored line on the test region indicates positive result. A procedural colored line on the control line region will always appear to serve as control”.

The test was interpreted as per the manufacturer's criteria as follows: positive test: if the white line on the test strip changes to red; this indicates serum HBsAg titre of $\geq 1 \mathrm{ng} / \mathrm{ml}$. Negative test; no color change indicates serum HBsAg titer of zero or below the detection level of the test.

Data analysis was performed using the Statistical Package for Social Sciences (SPSS) software version 18 (SPSS Inc., Chicago, Illinois, USA). Descriptive statistics yielded percentages, frequencies and proportions; Comparative statistical tests for significance of observed intergroup differences utilized chi square for categorical variables and student-t test for continuous variables. For all comparisons, significance level was at $\mathrm{p}<0.05$.

\subsection{Eligibility}

All consecutively presenting, and consenting, patients who accessed ophthalmic surgical care at the study center during the 6-month study period were included in the study. Non-consenting patients and patients who had non-surgical treatments were excluded from the study.

\subsection{Ethics}

Ethics approval compliant with the 1964 Helsinki Declaration on research involving human subjects as amended in London 2008 was obtained from the Medical and Health Research Ethics Committee (Institutional Review Board) of the study center. Informed consent was received from the patients.

\section{Results}

A total of 100 patients comprising 40 (40.0\%) males and 60 (60.0\%) females (Male: Female, 1:1.5) aged $52.9 \pm 15.4$ SD years (range 1 and 88 years) who had various ophthalmic surgeries at the study center during the study period constituted the participants. The average annual hospital admission is 226. The participant's socio-demographic profile is shown in Table 1 . The participants were predominantly farmers- 45 (45.0\%) and their leading clinical ophthalmic diagnoses necessitating surgical intervention were cataract-58 (58.0\%) and glaucoma (16.0\%), Table 2 and Table 3. Of the participants, only 2 (2.0\%) were seropositive for HbsAg. The two, both females aged between 21 - 40 years, comprised a student and a civil servant. The surgical procedure performed on them was evisceration; in one and cataract extraction in the other.

Table 1. Demographic characteristics of participants.

\begin{tabular}{|c|c|c|c|}
\hline \multirow{2}{*}{ Age range (years) } & \multicolumn{2}{|c|}{ Sex } & \multirow{2}{*}{ Total $(\%) n=100$} \\
\hline & Male & Female & \\
\hline $1-10$ & 1 & 1 & $2(2.0)$ \\
\hline $11-20$ & 0 & 1 & $1(1.0)$ \\
\hline $21-30$ & 4 & 2 & $6(6.0)$ \\
\hline $31-40$ & 5 & 4 & $9(9.0)$ \\
\hline $41-50$ & 5 & 21 & $26(26.0)$ \\
\hline $51-60$ & 10 & 15 & $25(25.0)$ \\
\hline $61-70$ & 12 & 12 & $24(24.0)$ \\
\hline $71-80$ & 3 & 3 & $6(6.0)$ \\
\hline $81-90$ & 0 & 1 & $1(1.0)$ \\
\hline Total & 40 & 60 & $100(100.0)$ \\
\hline
\end{tabular}


Table 2. Occupational distribution of participants.

\begin{tabular}{cc}
\hline Occupation & Number $(\%) \mathrm{n}=100$ \\
Farmers & $45(45.0)$ \\
Traders & $23(23.0)$ \\
Civil servants & $11(11.0)$ \\
Artisan & $10(10.0)$ \\
Pensioners & $6(6.0)$ \\
Students & $5(5.0)$ \\
Total & $100(100)$ \\
\hline
\end{tabular}

Table 3. Distribution of surgical procedures performed on the patients.

\begin{tabular}{cc}
\hline Surgical procedure & Number $(\%) \mathrm{n}=100$ \\
\hline Cataract surgery & $58(58.0)$ \\
Trabeculectomy & $16(16.0)$ \\
Evisceration & $10(10.0)$ \\
Pterygium excision & $7(7.0)$ \\
Combined cataract and trabeculectomy surgery & $4(4.0)$ \\
Incision and curettage of chalazia & $2(2.0)$ \\
Canthoplasty & $1(1.0)$ \\
Corneal repair & $1(1.0)$ \\
Conjuctival cyst excision & $1(1.0)$ \\
Total & $100(100)$ \\
\hline
\end{tabular}

HBV seropositivity did not show any significant association with participant's gender (Fisher's exact test, $\mathrm{p}=$ 0.5152), age (student-t test; mean age of HBV positives vs mean age of HBV negatives; $53.4 \pm 15.2 \mathrm{SD}$ vs $30.0 \pm$ 4.2SD; $\mathrm{p}=0.207$; $\mathrm{CI},-44.89--1.95)$ or occupation $(\mathrm{p}=0.928)$.

\section{Discussion}

During the period under review more females than males who were frequently aged 40 years or older accessed ophthalmic surgical care at the study center. This differs from other similar studies [17] [18] which reported variable degrees of male gender preponderance. The observed gender distribution could be attributed to reported higher prevalence of surgical eye diseases in females [19]. Additionally, this may be partly accounted for by the positive impact of the sustained public health education aimed at eliminating gender bias in the uptake of health care services particularly, in rural areas [20]. Efforts to sustain the campaign for gender equity in access to health services through public health education, pro-female gender economic empowerment and cross-gender affordability of health services are highly indicated.

The observed age characteristic consistent with the findings in related studies [16] [20]-[22] is attributable to the dominance of cataract often an age-related surgical eye disease, among the participants in the present and previous surveys [17] [21]-[23]. The present age data underscores the need for eye-care planners, implementers and eye health policy makers to deploy the necessary resources and logistics for cataract surgical care in the elderly especially in rural areas.

Although the observed 2.0\% seroprevalence of HBV infection in this study is low, it is comparable to the $1.7 \%$ reported by Alhassan et al. [17] in an urban Nigerian survey. The present finding suggests that rural versus urban location probably does not influence HBV sero-prevalence burden. The observed low prevalence however does not downgrade the risk of peri-operative cross-infection to health workers. While standard universal measures for prevention of cross infection from patient to eye care personnel should be observed in all patients irres- 
pective of serology status, pre-operative testing will help the health care personnel to exercise extra caution such as handling of surgical instruments and also enable the patient to seek early medical treatment. A uniform cross socio-economic cadre approach to advocacy for prevention of HBV infection is recommended. Towards this end, health education, immunization of the general public especially at-risk health workers and provision of affordable medical treatment are therefore instructive. The average monthly cost for the various drug treatment regimen of chronic Hepatitis B infection varies from 422 USD to 2940 USD [24]. This is obviously beyond the economic reach of those requiring treatment in this rural populace where majority are peasant farmers.

One hundred percent of those with HBV infection in our cohort are females. This differed from the male gender preponderance of 59.18\% reported by Naeem et al. [18] Possible cross infection with contaminated instruments used during the widely practiced female genital mutilation in Ebonyi state [25] may account for the observed female dominance. To this end, dangerous social practice tailored intervention targeting the female gender through aggressive public health education and legislation are warranted.

The extrapolation of the conclusions drawn from this study is limited by its one-center design, relatively low study participants, rural setting and reliability of the sensitivity of the test kit used for the study. A multi-center, larger participant survey preferable involving diverse hospitals and care settings is suggested.

\section{Conclusion}

There is a low sero-prevalence of HBV among ophthalmic surgical patients at PJH Uburu, Ebonyi state, Nigeria. HBV seropositivity was not associated with gender, age or occupation. Standard preventive measures during outpatient and perioperative ophthalmic care to prevent cross infection from patient to eye care personnel, immunisation of surgical eye care providers and mandatory pre-operative HBV screening are hereby advocated.

\section{Conflict of Interest}

None declared.

\section{External Source of Funding}

The authors declare no external source of funds for this work.

\section{References}

[1] Barker, L.F., Shulman, N.R., Murray, R., et al. (1970) Transmission of Serum Hepatitis. Journal of the American Medical Associations, 276, 841-844. http://dx.doi.org/10.1001/jama.1996.03540100085042

[2] Williams, R. (2006) Global Challenges of Liver Disease. Hepatology, 44, 521-526. http://dx.doi.org/10.1002/hep.21347

[3] Hepatitis, B. World Health Organization (WHO). http://www.who.int/mediacentre/factsheets/fs204/en/

[4] Moyer, L.A. and Mast, E.E. (1994) Hepatitis B: Virology, Epidemiology, Disease, and Prevention and an Overview of Viral Hepatitis. American Journal of Preventive Medicine, 10, 45-55.

[5] Maddrey, W.C. (2000) Hepatitis B: An Important Public Health Issue. Journal of Medical Virology, 61, 362-366. http://dx.doi.org/10.1002/1096-9071(200007)61:3<362::AID-JMV14>3.0.CO;2-I

[6] Coopstead, L.C. (2010) Pathophysiology. Saunders Press, Missouri, 886-887.

[7] Sleisenger, M.H., Feldman, M. and Friedman, L.S. (2006) Fordtran’s Gastrointestinal and Liver Disease: Pathophysiology, Diagnosis, Management. Saunders Press, Philadelphia.

[8] Kidd-Ljunggren, K., Holmberg, A., Bläckberg, J. and Lindqvist, B. (2006) High Levels of Hepatitis B Virus DNA in Body Fluids from Chronic Carriers. Journal of Hospital Infection, 64, 352-357. http://dx.doi.org/10.1016/j.jhin.2006.06.029

[9] Hepatitis B FAQs for the Public-Transmission. United State Centers for Disease Control and Prevention (CDC). http://www.cdc.gov/hepatitis/b/bfaq.htm\#transmit

[10] Emechebe, G.O., Emodi, I.J., Ikemefuna, A.N., Ilechukwu, G.C., Igwe, W.C., Ejiofor, O.S., et al. (2009) Hepatitis B Virus Infection in Nigeria-A Review. Nigerian Medical Journal, 50, 18-22.

[11] Odusanya, O.O., Alufohai, F.E., Meurice, F.P., Wellens, R., Weil, J. and Ahonkhai, V.I. (2005) Prevalence of Hepatitis B Surface Antigen in Vaccinated Children and Controls in Rural Nigeria. International Journal Infectious Disease, 9, 139-143. http://dx.doi.org/10.1016/j.ijid.2004.06.009 
[12] Alikor, E.A. and Erhabor, O.N. (2007) Seroprevalence of Hepatitis B Surface Antigenaemia in Children in a Tertiary Health Institution in the Niger Delta of Nigeria. Nigerian Journal of Medicine, 16, 250-251.

[13] Tswana, S., Chetsanga, C., Nystrom, L., Moyo, S., Nzara, M. and Chieza, L. (1996) A Sero-Epidemiological CrossSectional Study of Hepatitis B Virus in Zimbabwe. South African Medical Journal, 86, 72-75.

[14] Ugwuja, E.I. (2010) Seroprevalence of Hepatitis B Surface Antigen and Liver Function Tests among Adolescents in Abakaliki, South-Eastern Nigeria. Internet Journal of Tropical Medicine, 6, 1-6.

[15] Shahnaz, S., Reza, B. and Seyed-Moayed, A. (2005) Risk Factors for Chronic Hepatitis B Infection: A Case Controlled Study. Hepatitis Monthly, 5, 109-115.

[16] Seyed-Moayed, A. (2006) Immunization, an Important Strategy to Control Hepatitis. Hepatitis Monthly, 6, 3-5.

[17] Alhasan, M.B., Unung, P. and Adejor, G.O. (2013) HIV and HBsAg Seropositivity amongst Patients Presenting for Ocular Surgery at a Tertiary Eye Care Hospital in Nigeria. Open Journal of ophthalmology, 22, 18-19. http://dx.doi.org/10.2174/1874364101307010018

[18] Naeem, S.S., Siddiqui, E.U., Kazi, A.N., Khan, S.T., Abdullah, F.E. and Adhi, I. (2012) Prevalence of Hepatitis B and Hepatitis C among Preoperative Cataract Patients in Karachi. BMC Research Notes, 5, 492. http://dx.doi.org/10.1186/1756-0500-5-492

[19] Lewallen, S. and Courtright, P. (2002) Gender and Use of Cataract Surgical Services in Developing Countries. Bulletin of World Health Organization, 80, 300-303.

[20] AMURT Starts Work in Nigeria. www.africa.amurt.net/nigeria

[21] Okoye, O., Magulike, N. and Chuka-Okosa, C. (2012) Prevalence of Human Immunodeficiency Virus Seropositivity among Eye Surgical Patients at a Rural Eye Care Facility in South-Eastern Nigeria. Middle East African Journal of Ophthalmology, 19, 93-96. http://dx.doi.org/10.4103/0974-9233.92122

[22] Ezegwui, I.R., Akariwe, N.N. and Onwasigwe, E.N. (2012) HIV Seroprevalence in Ophthalmic Surgery Patients at ESUT Teaching Hospital Enugu. Nigerian Journal of Medicine, 21, 194-195.

[23] Eze, B.I. (2013) Audit of Ophthalmic Surgical Interventions in a Resource-Deficient Tertiary Eye Care Facility in SubSaharan Africa. Journal of Health Care for the Poor and Underserved, 24, 197-205. http://dx.doi.org/10.1353/hpu.2013.0013

[24] Approved HBV Antiviral and Interferon Therapy Cost Comparison 2011. Hepatitis B Foundation. www.hepb.org/2011_drug_comparison

[25] Ibekwe, P.C., Onoh, R.C., Onyebuchi, A.K., Ezeonu, P.O. and Ibekwe, R.O. (2012) Female Genital Mutilation in Southeast Nigeria: A Survey on the Current Knowledge and Practice. Journal of Public Health and Epidemiology, 4, 117-122. 